\title{
A CONSTRUÇÃO SOCIAL DO PÚBLICO ALVO E O DESENHO DA POLÍTICA PÚBLICA: ANÁLISE COMPARATIVA DA OPERAÇÃO CENTRO LEGAL E DO PROGRAMA DE BRAÇOS ABERTOS
}

\author{
THE SOCIAL CONSTRUCTION OF TARGET POPULATION AND THE POLICY \\ DESIGN: COMPARATIVE ANALYSIS OF THE LEGAL CENTRO OPERATION AND THE \\ PROGRAM OF OPEN ARMS
}

Matheus Silveira de Souza ${ }^{1}$

\section{RESUMO}

O estudo sobre a construção social e o desenho das políticas públicas evidencia que os públicos alvos das políticas tendem a receber uma quantidade maior ou menor de benefícios ou sanções de acordo com a construção social de sua imagem, de modo que a política pública terá um desenho diferente dependendo de qual grupo será seu destinatário. Nesse sentido, a pesquisa tem o objetivo de analisar a política pública de drogas desenvolvida no município de São Paulo para os usuários de crack, comparando as políticas Operação Centro Legal e o Programa De Braços Abertos. Desse modo, busca-se encaixar o público alvo de usuários de crack na tabela desenvolvida por Scheneider, Ingram e Deleon, com o objetivo de desvelar como a construção social da imagem desse grupo afeta na efetividade da política pública de drogas no município de São Paulo. O método usado para alcançar os objetivos foi a revisão bibliográfica e a análise qualitativa dos dados expedidos pelo governo municipal de São Paulo e pela Fiocruz. Por fim, concluiuse que o poder político do público alvo, a sua imagem perante a sociedade, bem como o encaixe desse público em um ou outro grupo social são fatores essenciais para a efetividade da política pública e a distribuição de benefícios e sanções.

PALAVRAS-CHAVE: Construção social de público alvo; Desenho da política pública; Cracolândia.

\begin{abstract}
The study about social construction of target population and policy design shows that target audiences of policies tend to receive a greater or lesser amount of benefits or sanctions according to the social construction of their image, so the public policy will have a different design depending on which group will be your

${ }^{1}$ Graduado em Direito pela PUC-PR. Especialista em Direito Constitucional pelo IDCC. Mestrando em Direito do Estado pela USP. Vinculado à Faculdade de Direito da Universidade de São Paulo (Largo São Francisco), reside em São Paulo/SP. Contato: mathmss94@gmail.com
\end{abstract}


SOUZA, Matheus Silveira de. A Construção Social do Público Alvo e o desenho da Política Pública: análise comparativa da operação centro legal e do programa de braços abertos. Revista Eletrônica Direito e Política, Programa de Pós-Graduação Stricto Sensu em Ciência Jurídica da UNIVALI, Itajaí, v.14, n.2, $2^{\circ}$ quadrimestre de 2019. Disponível em: www.univali.br/direitoepolitica - ISSN 19807791

receiver. In this sense, the research has the objective of analyzing the public policy developed in the city of São Paulo for users of crack, comparing the policies Operation Legal Center and the Open Arms Program. Thus, it is seek to fit the group of users of crack in the table developed by Scheneider, Ingram and Deleon, with the aim of revealing how the social construction of the image of this group affects the effectiveness of public drug policy in the city of São Paulo. The method used to reach the objectives was the bibliographical review and the analysis of the data sent by the City Hall of São Paulo and Fiocruz. Finally, it was concluded that the political power of the target public, its image before society, as well as the fit of this public in one or another social group are essential factors for the effectiveness of public policy and the distribution of benefits and sanctions.

KEYWORDS: Social Construction of target populatiton; Policy Design; Crackland.

\section{INTRODUÇÃO}

O estudo de políticas públicas tem ganhado cada vez mais espaço na academia, sendo objeto de estudo de diversas áreas do conhecimento, como ciência política, educação, gestão pública e direito. Assim, pode-se apontar que a análise das políticas públicas, pelo menos na área do direito e da ciência política, costuma focar, principalmente, em quatro perspectivas diferentes, a saber: os grupos de interesse atuando junto aos tomadores de decisão, recursos de poder, leis que regulamentam as políticas públicas e instituições que delimitam a ação governamental.

Entretanto, por mais proveitosas e úteis que sejam tais perspectivas, elas são incapazes de captar alguns pontos relevantes das políticas públicas e de responder algumas questões. Nesse sentido, o estudo da construção social do público alvo e do desenho de determinada política pública (social construction of target population and policy design) trás luz às questões ainda obscuras e pouco elucidadas pelos quadros de análise mais tradicionais. Isto porque, tal perspectiva parte da premissa de que há a construção social de uma imagem, positiva ou negativa, dos grupos que receberão determinada política pública, sendo que a distribuição que a policy fará de benefícios ou sanções pode variar de acordo com o público alvo que receberá essa política. 
SOUZA, Matheus Silveira de. A Construção Social do Público Alvo e o desenho da Política Pública: análise comparativa da operação centro legal e do programa de braços abertos. Revista Eletrônica Direito e Política, Programa de Pós-Graduação Stricto Sensu em Ciência Jurídica da UNIVALI, Itajaí, v.14, n.2, $2^{\circ}$ quadrimestre de 2019. Disponível em: www.univali.br/direitoepolitica - ISSN 19807791

Tendo como pano de fundo a problemática acima exposta, a presente pesquisa focará na política pública desenvolvida pelo governo municipal e estadual no município de São Paulo com os usuários de crack que ocupam a denominada "cracolândia". Nessa esteira, busca-se encaixar o público alvo apontado na tabela desenvolvida por Scheneider, Ingram e Deleon, com o objetivo de desvelar como a construção social da imagem dos usuários de crack afeta na efetividade da política pública de drogas no município de São Paulo.

Após discorrer brevemente sobre o conceito de social construction and policy design, será analisado e, posteriormente, estabelecida uma comparação entre os programas desenvolvidos no município que apresentavam soluções ao problema do crack, quais sejam, operação "Centro Legal" e programa "De Braços Abertos". Posteriormente, usando como referência o texto de True, D. Jones e Baumgartner², almeja-se verificar quais condições materiais e políticas tornaram possível uma mudança de diretriz nas políticas públicas analisadas.

O artigo possui como metodologia a revisão bibliográfica e busca atingir seus objetivos a partir da utilização do quadro de análise desenvolvido por Scheneider, Ingram e Deleon. ${ }^{3}$ Os dados quantitativos utilizados na pesquisa foram tirados tanto de fontes primárias - informados pelo sítio eletrônico da Prefeitura de São Paulo e pela pesquisa da Fiocruz sobre o uso de crack - como de fontes secundárias, tais como a dissertação de mestrado de Carvalhido. ${ }^{4}$

É importante ressaltar que o presente artigo leva em consideração a complexidade multifatorial e multidisciplinar que permeia a discussão sobre a adicção de drogas, especialmente o crack. Assim, o debate envolve relevantes questões de ordem sociológica, de saúde, assistência social, psicologia, não se limitando ao âmbito do direito e da ciência política. Todavia, buscando um recorte temático mais preciso à investigação, bem como maior rigidez metodológica, a pesquisa não abordará

\footnotetext{
2 TRUE, James L; JONES, Bryan D; BAUMGARTNER, Frank R. Punctuated-Equilibrium Theory: Explaining Stability and Change in Public Policymaking. In: SABATIER, Paul (ed.) - Theories of Policy Process - Boulder: Westview Press, 2007

3 INGRAM, Helen; SCHNEIDER, Anne; DELEON, Peter. Social Construction and Policy Design. In: SABATIER, Paul. Theories of Policy Process. Califórnia: Westview Press, 2007.

${ }^{4}$ CARVALHIDO, Anna Luísa. O estigma e o poder do conhecimento: um estudo sobre a operação Centro Legal de 2012. 2014. 138 f. (Dissertação) Mestrado em Direito. Faculdade de Direito, Fundação Getúlio Vargas, São Paulo. 2014
} 
SOUZA, Matheus Silveira de. A Construção Social do Público Alvo e o desenho da Política Pública: análise comparativa da operação centro legal e do programa de braços abertos. Revista Eletrônica Direito e Política, Programa de Pós-Graduação Stricto Sensu em Ciência Jurídica da UNIVALI, Itajaí, v.14, n.2, $2^{\circ}$ quadrimestre de 2019. Disponível em: www.univali.br/direitoepolitica - ISSN 19807791

varios fatores que envolvem o tema, mas sim, guardará atenção para a construção social do público alvo dos usuários de crack e a influência dessa imagem social na construção do desenho da política pública, bem como sua recíproca.

\section{CONSTRUÇÃO SOCIAL DA IMAGEM, DESENHO DA POLÍTICA PÚBLICA E CAPITAL POLÍTICO DISPONÍVEL}

A forma de dimensionar a probabilidade dos grupos serem bem sucedidos ou não em uma policy se dá em dois níveis concomitantes. O primeiro diz respeito ao poder político que tal grupo possui, como por exemplo, o dinheiro para financiar campanhas, o tempo gasto no lobby, a capacidade de lobby, a organização ou não do grupo, etc.

O segundo nível que deve ser aferido diz respeito a imagem que aquele grupo possui perante a sociedade como maior ou menor merecedor de benefícios. Visando ilustrar o problema, pode-se apontar, hipoteticamente, dois grupos distintos: pequenos empresários e ex presidiários. Dessa forma, uma política pública de fomento ao emprego ou de saúde variará enormemente na distribuição de benefícios e encargos (benefits and burdens) dependendo de qual desses grupos será o seu público alvo, em virtude da imagem positiva ou negativa que possuem, bem como do poder político que dispõe. Levando em consideração as duas formas de dimensionar a influência dos grupos na política pública, será usado a tabela de Scheneider, Ingram e Deleon ${ }^{5}$ para verificar a posição dos usuários de crack comparados a outros grupos.

\footnotetext{
5 INGRAM, Helen; SCHNEIDER, Anne; DELEON, Peter. Social Construction and Policy Design. In: SABATIER, Paul. Theories of Policy Process. Califórnia: Westview Press, 2007.
} 
SOUZA, Matheus Silveira de. A Construção Social do Público Alvo e o desenho da Política Pública: análise comparativa da operação centro legal e do programa de braços abertos. Revista Eletrônica Direito e Política, Programa de Pós-Graduação Stricto Sensu em Ciência Jurídica da UNIVALI, Itajaí, v.14, n.2, 20 quadrimestre de 2019. Disponível em: www.univali.br/direitoepolitica - ISSN 19807791

\section{QUADRO DE ANÁLISE 6 \\ CONSTRUÇÃO SOCIAL DA IMAGEM}

Positiva

Negativa

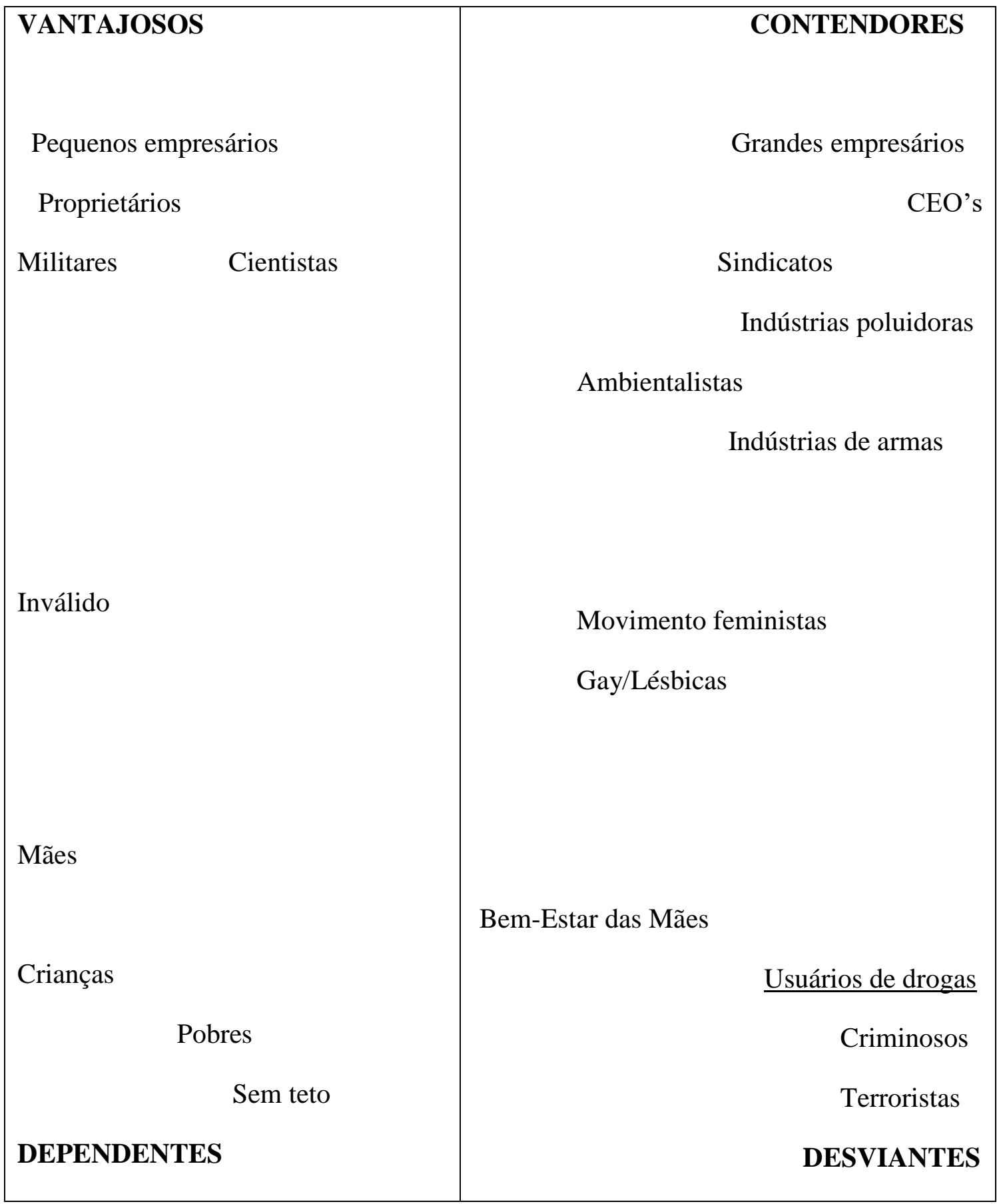

${ }^{6}$ Tradução nossa. 
SOUZA, Matheus Silveira de. A Construção Social do Público Alvo e o desenho da Política Pública: análise comparativa da operação centro legal e do programa de braços abertos. Revista Eletrônica Direito e Política, Programa de Pós-Graduação Stricto Sensu em Ciência Jurídica da UNIVALI, Itajaí, v.14, n.2, $2^{\circ}$ quadrimestre de 2019. Disponível em: www.univali.br/direitoepolitica - ISSN 19807791

Como se vê, ainda que a Constituição estabeleça que todos são iguais perante a lei, o estudo da construção social (social construction) revela que os tomadores de decisão tratam as pessoas de forma diferente quando da elaboração e construção das políticas públicas, dependendo do público destinatário de tais políticas.

Antes de adentrar ao exame do quadro, algumas considerações devem ser feitas. Embora o quadro de análise tenha sido elaborado levando em conta a realidade dos Estados Unidos, optou-se por usá-lo como referência na presente pesquisa em virtude da ausência de quadros de análise elaborados na literatura brasileira sobre essa temática. Assim, ainda que a transposição do quadro para o contexto do Brasil possua limitações, acredita-se que há pontos de ligação entre a realidade dos dois países, que permitem a extração de inferências à pesquisa.

O quadro de análise busca medir duas dimensões da construção social, a saber, a imagem (positiva ou negativa) que cada grupo possui enquanto maior ou menor merecedor de um benefício, bem como sua influência política. A linha horizontal do quadro mensura a imagem de cada público alvo, sendo que quanto mais o grupo estiver para a direita, pior será sua imagem enquanto merecedor de benefícios de uma política pública. A linha vertical mede a influência política do grupo, de forma que quanto mais próximo do topo, maior é o capital político do grupo. Conforme já exposto, o capital político dos grupos refere-se ao dinheiro disponível para financiar campanhas, o tempo gasto no lobby, a capacidade de lobby, a organização ou não do grupo, entre outras coisas. A imagem, por sua vez, refere-se ao merecimento ou não de benefícios e encargos conferidos pelas políticas públicas. Não se pode ignorar que a construção da imagem emana de diversas fontes da sociedade, sendo o desenho da política pública apenas uma delas. Vale apontar, ainda, que tais posicionamentos dos grupos não são necessariamente fixos, de modo que os públicos alvos podem ocupar um ou outro agrupamento, dependendo do desenho da política pública, bem como de outras fontes de construção social.

Assim, pode-se visualizar a caracterização de quatro grupos existentes: vantajosos, contendores, dependentes e desviantes. Assim, algumas breves 
SOUZA, Matheus Silveira de. A Construção Social do Público Alvo e o desenho da Política Pública: análise comparativa da operação centro legal e do programa de braços abertos. Revista Eletrônica Direito e Política, Programa de Pós-Graduação Stricto Sensu em Ciência Jurídica da UNIVALI, Itajaí, v.14, n.2, $2^{\circ}$ quadrimestre de 2019. Disponível em: www.univali.br/direitoepolitica - ISSN 19807791

considerações tornam-se importantes sobre cada um dos grupos, conforme a caracterização estabelecida por Scheneider, Ingram e Deleon?

a) Os vantajosos possuem alto capital político e desfrutam de uma imagem construída socialmente como merecedores. Assim, é frequente que esse grupo seja um público alvo nas políticas públicas que receba muitos benefícios e poucas sanções, além de ser tratado como um público que ajuda na construção da Nação. Esse grupo inclui pequenos empresários, proprietários, cientistas, militares, etc.

b) Os contendores possuem alta influência política mas, em contrapartida, dispõe de uma imagem negativa enquanto merecedores de benefícios. Esse grupo contem as industrias poluidoras, sindicatos, ativistas conservadores entre outros. Esse grupo também possui alguma probabilidade de receber benefícios nas políticas públicas, em virtude da sua alta influência política, todavia tais benefícios são escondidos no detalhamento da legislação e mais difíceis de serem percebidos, tendo em vista que não é vantajoso politicamente conceder benefícios a grupos com uma má imagem construída socialmente.

c) Os dependentes possuem uma boa construção social de sua imagem, enquanto merecedores de benefícios de políticas públicas. Entretanto, a falta de influência política desse grupo faz com que os benefícios a eles concedidos sejam quase sempre limitados e incapazes de solucionar os problemas aos quais estão expostos. Esse grupo é composto por orfãos, doentes mentais, sem teto, famílias pobres e etc. A noção difundida de que esse grupo pouco faz para a evolução da Nação faz com que, embora tenham uma boa construção social, sejam considerados menos merecedores de benefícios que os vantajosos.

d) Por fim, o grupo dos desviantes não possui poder político e dispõe de uma péssima imagem construída socialmente, como não merecedores dos benefícios de uma política pública. Nesse sentido, tal grupo costuma receber uma grande quantidade de encargos e sanções e quase nenhum benefício.

\footnotetext{
7 INGRAM, Helen; SCHNEIDER, Anne; DELEON, Peter. Social Construction and Policy Design. In: SABATIER, Paul. Theories of Policy Process. Califórnia: Westview Press, 2007.
} 
SOUZA, Matheus Silveira de. A Construção Social do Público Alvo e o desenho da Política Pública: análise comparativa da operação centro legal e do programa de braços abertos. Revista Eletrônica Direito e Política, Programa de Pós-Graduação Stricto Sensu em Ciência Jurídica da UNIVALI, Itajaí, v.14, n.2, $2^{\circ}$ quadrimestre de 2019. Disponível em: www.univali.br/direitoepolitica - ISSN 19807791

Esse público costuma ser composto por criminosos, terroristas ou suspeitos de terrorismo, traficantes, usuários de drogas, hackers, estupradores, entre outros. $^{8}$

Levando em consideração que o público analisado pelo atual trabalho, usuários de crack, encontram-se frequentemente na categoria dos desviantes, algumas considerações adicionais merecem ser feitas a respeito desse grupo. Primeiramente, percebe-se que os usuários ocupam o lugar mais prejudicado do quadro de análise, enquanto grupo com pior imagem construída e menor capital político, compartilhando esse espaço com criminosos, terroristas, estupradores, entre outros. Tal posicionamento já mostra certa tendência desse público alvo ser mais prejudicado do que beneficiado nas políticas públicas.

É relevante destacar o papel da mídia, ao lado do governo, na construção da imagem desses grupos e no envio dessas mensagens à população. Para ilustrar o papel da mídia nessa relação, pode-se destacar a pesquisa de Romanini e Roso, que monitorou as matérias sobre crack veiculadas nos três maiores jornais do Rio Grande do Sul entre o período de julho de 2008 e julho de 2009. Foi constatado que o Crack é a única droga citada em 67\% destas reportagens, contra 4,6\% da maconha, $7,3 \%$ da cocaína, $2,8 \%$ do álcool, 0,9\% do cigarro 9 .

Sobre as consequências do uso do Crack, algumas matérias (19,3\%) não abordam essa questão. As matérias que tratam de tal assunto apontam como consequências: Delinquência/Criminalidade (19,3\%); Privação de Liberdade $(12,8 \%)$; Violência praticada por usuários $(11,9 \%)$; Morte do usuário $(9,2 \%)$; Terapêutica (6,4\%); Envolvimento com grupos criminosos/gangues, Problemas de Saúde e Problemas na família (5,5\%); Outros (1,8\%); e Violência sofrida por usuários $(0,9 \%)$.

Nessa linha de raciocínio, aponta-se que o grupo dos desviantes costuma ser culpado por boa parte dos problemas do país, que em verdade decorrem de

\footnotetext{
8 INGRAM, Helen; SCHNEIDER, Anne; DELEON, Peter. Social Construction and Policy Design. In: SABATIER, Paul. Theories of Policy Process. Califórnia: Westview Press, 2007.

9 ROMANINI, M.; ROSO, A. O Crack na Mídia Escrita: epidêmico, avassalado e diabólico. In: Anais da $3^{\circ}$ Jornada Interdisciplinar em Saúde. Santa Maria, 2010.
} 
SOUZA, Matheus Silveira de. A Construção Social do Público Alvo e o desenho da Política Pública: análise comparativa da operação centro legal e do programa de braços abertos. Revista Eletrônica Direito e Política, Programa de Pós-Graduação Stricto Sensu em Ciência Jurídica da UNIVALI, Itajaí, v.14, n.2, $2^{\circ}$ quadrimestre de 2019. Disponível em: www.univali.br/direitoepolitica - ISSN 19807791

questões econômicas e sociais amplas. Fazendo um paralelo com os usuários de crack no Brasil, não é difícil perceber o quanto de mensagens são enviadas, pela mídia e pelo Estado, que costumam colocar esse grupo como fonte dos males gerais do país. Portanto, problemas que encontram suas raízes em quase 400 anos de escravidão, na taxa de desigualdade social das mais elevadas no mundo, má distribuição de renda, entre outros fatores históricos, são resumidos em uma única palavra, que ganha uma dimensão demoníaca: crack.

Para ser mais exato, a dimensão monstruosa não está relacionada com a droga, tendo em vista que esta, por si só, não gera consequências negativas. Assim, a dimensão diabólica só aparece no momento da ingestão da droga por algum ser humano. Nessa perspectiva, a dita guerra as drogas não é contra estas, mas sim contra os usuários e traficantes. Entretanto, parte da população de classe média e classe alta não costuma ter problemas tão frequentes com o uso de drogas, de modo que os problemas são mais persistentes em uma parcela com classe social bem estabelecida, motivo pelo qual a frase pode ser novamente reformulada: a guerra não é nem contra as drogas, nem contra o ser humano em geral. A guerra é contra a pobreza.

Essa afirmação ganha respaldo na pesquisa de Craig Reinarman ( The Social Construction of Drug Scare) ao apontar que o ópio e a cocaína eram amplamente usados nos EUA do século 20 e que sua criminalização só começou quando houve uma mudança na população de usuários, passando de predominantemente brancos, classe média e mulheres de meia idade para jovens, classe trabalhadora e americanos negros. ${ }^{10}$ Nessa lógica, visando ganhar apoio no Congresso Americano, os empreendedores morais começaram a enviar diversas mensagens, inclusive na imprensa, de que a cocaína induzia os americanos negros a cometerem estupro com as mulheres brancas. ${ }^{11}$

Nesse sentido, evidencia-se que a classe dos desviantes costuma ser alvo de políticas públicas de punição por parte dos políticos, como estratégia de ganho de capital político e aprovação popular. Isto porque, as diversas mensagens

10 REINARMAN, Craig. The Social Construction of Drug Scare. Wadsworth Publishing Co. 1994

${ }^{11}$ REINARMAN, Craig. The Social Construction of Drug Scare. p. 3. 
SOUZA, Matheus Silveira de. A Construção Social do Público Alvo e o desenho da Política Pública: análise comparativa da operação centro legal e do programa de braços abertos. Revista Eletrônica Direito e Política, Programa de Pós-Graduação Stricto Sensu em Ciência Jurídica da UNIVALI, Itajaí, v.14, n.2, $2^{\circ}$ quadrimestre de 2019. Disponível em: www.univali.br/direitoepolitica - ISSN 19807791

transmitidas responsabilizando esse grupo pelos problemas do país costumam estar internalizadas pela sociedade, de modo que a distribuição de sanções e punições a tais grupos é visto com bons olhos por grande parte da população. Uma agravante é que esse grupo, por não possuir quase que nenhuma influência política ou advocacy que lute por seus interesses, é um alvo fácil de ser atacado por políticas punitivistas e dificilmente terá mecanismos para se defender.

Buscando uma melhor compreensão desse grupo, algumas considerações são necessárias sobre o termo desviante (deviant). Para Becker, sociólogo norte americano de referência sobre o tema, o desvio é definido como um ato que desencadeia uma reprovação social. Portanto, os atos desviantes não possuem uma inerência qualitativa em termos absolutos, mas são um subproduto construído social e culturalmente. Dessa forma, a construção social dos desviantes é feito ao estipular leis cuja infração constitui um comportamento desviante. Desviantes não seria um grupo de pessoas, mas sim uma consequência pela infração de dispositivos legais. ${ }^{12}$ É possível focar não apenas na conduta dos denominados desviantes, mas sim na reação que resulta da prática dessas condutas. Em outras palavras e fazendo um paralelo com o público alvo ora pesquisado, pode-se focar não na conduta desviante do uso de crack, mas na reação dos policiais, dos formuladores de políticas públicas, da mídia e da própria população. ${ }^{13}$ Tal reação é importante pois ajuda a compreender como o Estado enxergará o problema e de quais meios irá dispor para apresentar soluções.

Dentre os conceitos desenvolvidos brevemente acima, pode-se evidenciar como a construção social da imagem do público alvo de uma política pública é determinante e serve de diretriz para a construção do desenho da política pública - e vice versa - bem como a consequente distribuição de benefícios e sanções. Em outras palavras, o grupo que será usuário da ação governamental é ponto determinante que direcionará como essa policy será construída, sempre levando em conta a distribuição de benefícios e encargos. Essa ideia é central no

\footnotetext{
12 BECKER, Howard. Outsiders: studies in the sociology of deviance. New York: Free Press, 1963.

${ }^{13}$ CARVALHIDO, Anna Luísa. O estigma e o poder do conhecimento: um estudo sobre a operação Centro Legal de 2012. 2014. 138 f. (Dissertação) Mestrado em Direito. Faculdade de Direito, Fundação Getúlio Vargas, São Paulo. 2014
} 
SOUZA, Matheus Silveira de. A Construção Social do Público Alvo e o desenho da Política Pública: análise comparativa da operação centro legal e do programa de braços abertos. Revista Eletrônica Direito e Política, Programa de Pós-Graduação Stricto Sensu em Ciência Jurídica da UNIVALI, Itajaí, v.14, n.2, $2^{\circ}$ quadrimestre de 2019. Disponível em: www.univali.br/direitoepolitica - ISSN 19807791

pensamento de Ingram, Schneider e Deleon, sendo uma das proposições formuladas pelas autoras:

Proposition 3. Policy design elements, including tools, rules and delivery structures differ according to the social construction and power of target groups. ${ }^{14}$

Dado a abordagem dos pontos teóricos feitos a partir do referencial Scheneider, Ingram e Deleon, visa-se inicialmente explicitar o que seria a Social Construction e Policy Design. Por conseguinte, o presente trabalho passará à análise da política pública Operação Centro Legal, desenvolvida por Serra e posteriormente por Alckimin.

Em outra margem, destaca-se que as estruturas de decisões nas políticas públicas costumam dividir-se em quatro: problemas, soluções, participantes e oportunidades de escolhas. Todavia, segundo Kingdom, nem sempre essas quatro divisões seguem uma ordem lógica. Assim, muitas vezes, ao invés de identificar o problema para, posteriormente, buscar a solução adequada para este, o que ocorre é que os policymakers possuem soluções previamente guardadas, esperando pelo aparecimento de problemas para encaixá-las neles. "More often solutions search problems"15 Um bom exemplo a ser citado é dos advogados, que aprendem a solução para os problemas e desenvolvem suas peças - modelos - antes mesmo destes chegarem até eles. Posteriormente, quando os problemas chegam, tentam anexar seus modelos nesses.

\section{PRIMEIRAS CONSIDERAÇÕES SOBRE A OPERAÇÃO CENTRO LEGAL}

O projeto Centro Legal e Nova Luz foi lançado em 2009, com articulação do Governo municipal e estadual, na gestão Kassab e Serra respectivamente. Esses projetos visavam apresentar uma solução para o problema do crack no município de São Paulo. O presente capítulo buscará identificar a imagem dos usuários de crack utilizado pelo Governo e as ações desenvolvidas, em tese, com o fim de

\footnotetext{
14 INGRAM, SCHNEIDER e DELEON. Social Construction and Policy Design. p. 13.

15 KINGDOM, John W. Agendas, Alternatives and Public Policies. New York: Longman, 1995
} 
SOUZA, Matheus Silveira de. A Construção Social do Público Alvo e o desenho da Política Pública: análise comparativa da operação centro legal e do programa de braços abertos. Revista Eletrônica Direito e Política, Programa de Pós-Graduação Stricto Sensu em Ciência Jurídica da UNIVALI, Itajaí, v.14, n.2, $2^{\circ}$ quadrimestre de 2019. Disponível em: www.univali.br/direitoepolitica - ISSN 19807791

solucionar o problema. Vale destacar que o projeto Nova Luz, de âmbito municipal, visava a restauração urbana da região da Luz em São Paulo, onde funcionava a denominada cracolândia. Assim, essa política pública focava em estratégias urbanísticas, não tendo como objetivo principal atuar diretamente com os usuários de crack. Tendo em vista essas estratégias, o presente trabalho fará um recorte temático, focando tão somente na operação Centro Legal, eis que essa que dispunha de ações ligadas diretamente ao combate ao crack.

A operação Centro Legal, inicialmente elaborada por José Serra enquanto Governador do Estado de São Paulo e continuada por Geraldo Alckimin em 2012, visava, em tese, uma atuação multifatorial, envolvendo órgãos estaduais e municipais ligados à saúde, segurança e assistência social. Assim, o Governo do Estado de São Paulo, por meio da Polícia Militar, a definiu como:

A operação integrada Centro Legal é constituída de atividades que envolvem as polícias e os órgãos estaduais e municipais ligados à segurança, saúde e assistência social. Seus objetivos são o resgate da cidadania, a elevação da dignidade humana por meio da reinserção social, a recuperação de áreas degradadas e o combate ao tráfico de drogas. ${ }^{16}$

Ora, conforme visualiza-se, a ideia inicial esboçada era de articular ações multidisciplinares para o enfrentamento de um problema muito complexo para ser resolvido apenas com repressão. Nesse sentido, seria possível descrever, levando em conta o recorte de Scheneider, Ingram e Deleon de políticas públicas como distribuidora de benefícios e sanções, que as ações descritas acima dos órgãos de saúde e assistência social seriam uma espécie de benefício (ao buscar resgatar a cidadania e elevar a dignidade por meio da reinserção social) e a segurança estaria na caixa das sanções, por envolver ações repressivas. Assim, segundo dados concedidos em entrevista na pesquisa de Anna Luiza Carvalhido ${ }^{17}$, a operação ocorreria em 3 fases, qual sejam:

\footnotetext{
${ }^{16}$ Carvalhido, Anna Luísa. O estigma e o poder do conhecimento: um estudo sobre a operação Centro Legal de 2012. 2014. 138 f. (Dissertação) Mestrado em Direito. Faculdade de Direito, Fundação Getúlio Vargas, São Paulo. 2014

${ }_{17}$ Carvalhido, Anna Luísa. O estigma e o poder do conhecimento: um estudo sobre a operação Centro Legal de 2012. p. 54.
} 
SOUZA, Matheus Silveira de. A Construção Social do Público Alvo e o desenho da Política Pública: análise comparativa da operação centro legal e do programa de braços abertos. Revista Eletrônica Direito e Política, Programa de Pós-Graduação Stricto Sensu em Ciência Jurídica da UNIVALI, Itajaí, v.14, n.2, $2^{\circ}$ quadrimestre de 2019. Disponível em: www.univali.br/direitoepolitica - ISSN 19807791

(fase 1) : quebrar a logística do tráfico com ações de polícia propriamente ditas e ações da Subprefeitura, com o objetivo de retirar traficantes, criando condições para a intervenção social e de saúde; (fase 2): ações sociais e de saúde voltada às pessoas em situação de vulnerabilidade, por meio de abordagens sociais, encaminhamento e tratamento, inclusive com moradias terapêuticas e inserção profissional; (fase 3): manutenção para que não se formem novamente esses grupos e espaços. E a fase mais difícil, porém importante, durante a qual se pretende encaminhar de imediato qualquer caso novo que eventualmente surja.

A elaboração da ação governamental em análise, com a distribuição não só de sanções, mas também de benefícios a um grupo que possui pouco capital político e uma imagem tão negativa, parece contrariar as hipóteses construídas por Ingram, de que tais grupos costumam ser alvos apenas de políticas punitivas e receber pouco (ou nenhum) benefício e muitas sanções. Entretanto, tal contradição estaria presente se nos limitássemos à análise apenas do plano abstrato do programa, sem focar em sua dimensão fática. Por conseguinte, distanciando-se do dever ser e olhando para o mundo do ser, observa-se quais das estratégias interventivas foram concretizadas pelo Governo do Estado e a hipótese de Ingram volta a ganhar força.

Em um primeiro momento, sublinha-se o espaço excessivo que a Polícia Militar preenchia na política pública em tela, ocupando um local central na operação ${ }^{18}$. Tal fato causa certa estranheza, pois uma policy multisetorial deveria contar com a polícia apenas como um dos braços disponíveis do programa, que em tese seria articulado com órgãos de saúde e assistência social. Assim, buscar-se-ia, de acordo com a descrição inicial da política, uma atuação integrada da Polícia Militar, Secretaria Municipal de Assistência Social, Secretaria de Saúde e Secretária de Estado da Justiça. Entretanto, o que se verificou foi uma atuação focada em estratégias de repressão, em que a Polícia Militar atuava quase que de maneira solitária na cracolândia. ${ }^{19}$ Vale destacar trechos da entrevista realizada com a

\footnotetext{
${ }^{18}$ Carvalhido, Anna Luísa. O estigma e o poder do conhecimento: um estudo sobre a operação Centro Legal de 2012.p 60

${ }^{19}$ Carvalhido, Anna Luísa. O estigma e o poder do conhecimento: um estudo sobre a operação Centro Legal de 2012. p 57
} 
SOUZA, Matheus Silveira de. A Construção Social do Público Alvo e o desenho da Política Pública: análise comparativa da operação centro legal e do programa de braços abertos. Revista Eletrônica Direito e Política, Programa de Pós-Graduação Stricto Sensu em Ciência Jurídica da UNIVALI, Itajaí, v.14, n.2, $2^{\circ}$ quadrimestre de 2019. Disponível em: www.univali.br/direitoepolitica - ISSN 19807791

capitã Leandra Pontes Dabagui no dia em que teve início a operação policial na cracolândia:

A operação visa a parte criminal, estabelecer a ordem para depois os funcionários da prefeitura irem ao local e encaminhar os usuários que quiserem para o tratamento. Por enquanto, só a polícia está na região, depois é que será feita a parte da saúde ${ }^{20}$.

Dessa forma, das 3 fases que a operação centro legal teria, conforme descrito acima, podemos notar que a política pública foi desenhada para cumprir, principalmente, a parte relacionada à repressão policial, de modo que a atuação da assistência social e da saúde ficou em segundo plano. A declaração de Luis Alberto Chaves de Oliveira, coordenador da Secretaria de Estado da Justiça, parece revelar quais eram as diretrizes de atuação do Governo do Estado:

A falta da droga e a dificuldade de fixação vão fazer com que as pessoas busquem o tratamento. Como é que você consegue levar o usuário a se tratar? Não é pela razão, é pelo sofrimento. Quem busca ajuda não suporta mais aquela situação. Dor e sofrimento fazem a pessoa pedir ajuda.

A declaração acima deu ao programa a alcunha de "política de dor e sofrimento", mostrando que a estratégia estaria em expor os usuários a abstinência para, a partir do sofrimento causado pela ausência da droga, levá-los a procurar ajuda na área de saúde. Essa atuação parece evidenciar que tratava-se muito mais de uma política pública de cunho criminal e repressivo-policial do que uma política social e de saúde. Nesse ponto, é possível encaixar a construção social da imagem dos usuários de crack, que não eram apenas desmerecedores de benefícios, mas também merecedores de sanções, traduzidas pelas palavras dor e sofrimento.

A tabela elaborada por Ingram e Schneider na Revista American Political Science Review $^{21}$ ganha relevância para 0 caso ora pesquisado, permitindo complementações. A tabela mostra os tipos de mensagens enviadas pelo Estado

20 (O Estado de S. Paulo, 4 de janeiro de 2012, "PM ocupa a cracolândia e fará vigilância 24 horas", Página 1).

21 INGRAM, Helen; SCHNEIDER, Anne. Social Construction of target Populations: Implications for Politics and Policy. In: The American Political Science Review, Vol. 87, N. 2, 1993.p. 9. 
SOUZA, Matheus Silveira de. A Construção Social do Público Alvo e o desenho da Política Pública: análise comparativa da operação centro legal e do programa de braços abertos. Revista Eletrônica Direito e Política, Programa de Pós-Graduação Stricto Sensu em Ciência Jurídica da UNIVALI, Itajaí, v.14, n.2, $2^{\circ}$ quadrimestre de 2019. Disponível em: www.univali.br/direitoepolitica - ISSN 19807791

aos grupos e à sociedade em relação aos diferentes públicos alvos, conforme já classificado anteriormente (vantajosos, competidores, dependentes e desviantes).

Da análise da tabela, pode-se verificar que as mensagens enviadas pelo Estado ao grupo dos desviantes é que eles são pessoas más, cujo comportamento constitui um problema à sociedade e que tendem a ser tratados pelo governo com desrespeito ou raiva ${ }^{22}$. Vale ressaltar as palavras das autoras sobre a questão:

The agenda, tools and rationales of policy impart messages to target population that inform them of their status as citizens and how them and people like themselves are liked to be treated by government

Nessa lógica, não parece forçoso afirmar que buscar a "dor e o sofrimento" de determinado grupo possa ser um tratamento desrespeitoso e consubstanciado pela raiva por parte do governo. Essa prática pode ser encontrada na matéria divulgada pelo jornal Estado de S. Paulo, logo no início da operação, que informava que a Polícia Militar havia usado balas de borracha para dispersar os usuários da região denominada como cracolândia. ${ }^{23}$ Da mesma forma, as diversas mensagens enviadas pela mídia e pelo governo apontando os usuários de crack como fonte de diversos problemas sociais também encaixam-se na perspectiva de que tal grupo constitui um problema para a sociedade.

Abaixo, será elencado os dados do programa, contando a atuação em todas as áreas, conforme disponibilizado pela Polícia Militar:

\begin{tabular}{|l|}
\hline 2.250 toneladas de lixo \\
\hline 517 prisões efetuadas \\
\hline 57.589 abordagens policiais \\
\hline 154 condenados capturados \\
\hline 440 flagrantes \\
\hline 86.919 abordagens sociais e de agentes de Saúde \\
\hline 24.872 encaminhamentos \\
\hline
\end{tabular}

22 INGRAM, Helen; SCHNEIDER, Anne. Social Construction of target Populations: Implications for Politics and Policy. p. 11

23 O Estado de S. Paulo, 6 de janeiro de 2012, "PM usa balas de borracha para dispersar usuários de drogas no centro", Cardeno Cotidiano, Página C1. 
SOUZA, Matheus Silveira de. A Construção Social do Público Alvo e o desenho da Política Pública: análise comparativa da operação centro legal e do programa de braços abertos. Revista Eletrônica Direito e Política, Programa de Pós-Graduação Stricto Sensu em Ciência Jurídica da UNIVALI, Itajaí, v.14, n.2, 20 quadrimestre de 2019. Disponível em: www.univali.br/direitoepolitica - ISSN 19807791

\begin{tabular}{|l|}
\hline 974 internações \\
\hline 80.535 atendimentos SMADS \\
\hline 728 informações CDR/COMUDA \\
\hline 13 atendimentos para tratamento CRATOD/SES \\
\hline 6 atendimentos para grávidas \\
\hline $66,300 \mathrm{~kg}$ de drogas apreendidas: \\
Crack $-5,291 \mathrm{~kg}$ \\
Cocaína $-17,121 \mathrm{~kg}$ \\
Maconha $-43,888 \mathrm{~kg}$ \\
\hline
\end{tabular}

Conforme os dados acima destacados, disponibilizados no site da Polícia Militar, pode-se fazer algumas considerações sobre a operação. Primeiro, ressalta-se que o número de atendimentos e internações realizadas, que é relativamente alto, carece de informações complementares. Isto porque, esse número leva em conta apenas a ida da pessoa para o tratamento, sem considerar a continuidade deste. Dessa forma, se o usuário vai para o tratamento ou internação e, no intervalo de um dia, desiste da abordagem terapêutica e retorna à cracolândia, computa-se da mesma maneira tais casos como abordagens ou internações. Outro fator que impede a compreensão mais ampla da efetividade de tais métodos é que não há dados ou quantificação quanto ao retorno dessas pessoas à cracolândia ${ }^{24}$. A constatação de que, após o início da operação, formou-se "filiais" da cracolândia por diversos pontos da cidade ${ }^{25}$ e o fluxo de usuários na região da Luz continuou elevado, parece apontar para o fato de que boa parte dessas abordagens e internações resultaram no retorno dos adictos aos pontos de uso.

Em relação às drogas apreendidas, os dados disponibilizados pelo Ministério Público quando da elaboração da Ação Civil Pública contra as ações da Operação Centro Legal, ajuda a elucidar a questão. Assim, somando a quantidade de todas

\footnotetext{
${ }^{24}$ Carvalhido, Anna Luísa. O estigma e o poder do conhecimento: um estudo sobre a operação Centro Legal de 2012. 2014. 138 f. (Dissertação) Mestrado em Direito. Faculdade de Direito, Fundação Getúlio Vargas, São Paulo. 2014

25 G1. "Um anos após operação no centro de sp cracolandia resiste e fanha filiais", de 03 de janeiro de 2012. Disponível em: http://g1.globo.com/sao-paulo/noticia/2013/01/um-ano-apos-operacaono-centro-de-sp-cracolandia-resiste-e-ganha-filiais.html.
} 
SOUZA, Matheus Silveira de. A Construção Social do Público Alvo e o desenho da Política Pública: análise comparativa da operação centro legal e do programa de braços abertos. Revista Eletrônica Direito e Política, Programa de Pós-Graduação Stricto Sensu em Ciência Jurídica da UNIVALI, Itajaí, v.14, n.2, $2^{\circ}$ quadrimestre de 2019. Disponível em: www.univali.br/direitoepolitica - ISSN 19807791

as drogas apreendidas no ano da operação e no ano anterior, aponta-se que em 2011 foram apreendidas 23.033,27 g e 19.286,6 g em 2012 (ano de início da operação). Portanto, conclui-se que a operação apreendeu 16,27\% a menos de droga do que no mesmo período analisado no ano anterior, quando esta ainda não havia iniciado ${ }^{26}$.

\section{CONCLUSÃO PRELIMINAR SOBRE A OPERAÇÃO CENTRO LEGAL}

Não se pode ignorar que a excessiva repressão policial acabou dificultando a abordagem da assistência social e da saúde, tendo em vista que os próprios usuários achavam que as "facilitadoras sociais" estavam a serviço da polícia. A operação afirmava ter como um dos maiores objetivos o "resgate de pessoas em estado de vulnerabilidade" É importante destacar o significado que o termo vulnerabilidade parece ter ganhado por parte do governo, sendo que os usuários eram tratados não como sujeitos de direito e cidadãos, mas sim como objetos que poderiam ser removidos do local públicamente indesejado, dado sua centralidade estratégica da região, dando um ar de higienização social ao ambiente. Assim, a vulnerabilidade ganha a conotação de pessoas incapazes de tomar decisão, possibilitando a tercerização de sua vontade para o Estado.

É importante atentar-se, mais uma vez, para o fato de que políticos, com frequência, usam de punições ao grupo dos desviantes para ganhar aprovação popular e capital político, de modo que distribuir sanções para grupos com imagem negativa pode ser uma boa vitrine eleitoral em épocas próximas da eleição ${ }^{27}$. Esse tipo de ação é estrategicamente vantajoso para os policymakers por dois motivos: 1) o grupo dos desviantes não possui influência política, de modo que dificilmente terão força para se defender de tais ataques; 2) a má imagem construída

\footnotetext{
${ }^{26}$ Carvalhido, Anna Luísa. O estigma e o poder do conhecimento: um estudo sobre a operação Centro Legal de 2012. 2014. 138 f. (Dissertação) Mestrado em Direito. Faculdade de Direito, Fundação Getúlio Vargas, São Paulo. 2014

27 INGRAM, Helen; SCHNEIDER, Anne; DELEON, Peter. Social Construction and Policy Design. In: SABATIER, Paul (ed.) - Theories of Policy Process - Boulder: Westview Press, 2007.
} 
SOUZA, Matheus Silveira de. A Construção Social do Público Alvo e o desenho da Política Pública: análise comparativa da operação centro legal e do programa de braços abertos. Revista Eletrônica Direito e Política, Programa de Pós-Graduação Stricto Sensu em Ciência Jurídica da UNIVALI, Itajaí, v.14, n.2, $2^{\circ}$ quadrimestre de 2019. Disponível em: www.univali.br/direitoepolitica - ISSN 19807791

socialmente gera não apenas a ideia de desmerecedores de benefícios, mas também de merecedores de punição.

Desse modo, umas das alternativas para a defesa de grupos desviantes é a intermediação de interesses por outras organizações com mais influência política e melhor imagem socialmente construída. Como exemplo no Brasil, pode-se citar a Conectas Direitos Humanos, o Instituto Sou da Paz, a Pastoral Carcerária, entre outras que atuam no Congresso Nacional e outras instâncias visando a proteção desse grupo e a fiscalização de ações realizadas na cracolândia. Uma das ações desenvolvidas pela Conectas foi a denúncia na ONU dos abusos cometidos na operação centro legal. ${ }^{28}$ Todavia, a efetividade de tais atos não costuma ser imediata, tendo mais o condão de pressionar o governo por meio do constrangimento perante a comunidade internacional, em virtude das constantes violações aos direitos humanos praticadas.

Retomando a discussão sobre as práticas de gentrificação, ressalta-se que essa lógica parece ser encontrada na operação Centro Legal, tendo em vista a extensiva repressão policial utilizada nas intervenções na cracolândia, como também a ideia de causar "dor e o sofrimento" nos usuários de crack. A própria portaria n. 105/2010, da Secretaria Municipal de Segurança Urbana, institucionalizou uma prática que pode ser considerada como de gentrificação, na medida em que buscou evitar indivíduos vulneráveis em locais impróprios para a permanência das pessoas. É o que aponta, ainda que de forma velada, a referida regulamentação:

Contribuir para diminuir e evitar a presença de pessoas em situação de risco nas vias e áreas públicas da cidade e locais impróprios para permanência saudável das pessoas.

Ainda que tal portaria tenha sido editada em âmbito municipal, sendo parte do programa Nova Luz, pode-se notar a articulação entre o governo estadual e municipal em liberar a área de indivíduos indesejáveis socialmente, guardando interesses alheios ao do bem estar dos usuários de crack.

28 ESTADÃO "Entidades denunciam na ONU violações na região central de SP", de 25 de janeiro de 2012. Disponível em: http://sao-paulo.estadao.com.br/noticias/geral,entidades-denunciam-naonu-violacoes-na-regiao-central-de-sp-imp-,8269 05Acesso em: 13/07/2017 
SOUZA, Matheus Silveira de. A Construção Social do Público Alvo e o desenho da Política Pública: análise comparativa da operação centro legal e do programa de braços abertos. Revista Eletrônica Direito e Política, Programa de Pós-Graduação Stricto Sensu em Ciência Jurídica da UNIVALI, Itajaí, v.14, n.2, 20 quadrimestre de 2019. Disponível em: www.univali.br/direitoepolitica - ISSN 19807791

Levando em conta o apanhado geral realizado, chama atenção a forma como o encaixe do público alvo da política pública no grupo de desviantes facilita e colabora para a distribuição de muitas sanções e pouco - ou nenhum - benefício. Essa distribuição é legitimada pela construção social realizada pelo governo, ao lado da mídia, ganhando respaldo da própria opinião pública. Dessa forma, ainda que o problema não seja resolvido, a punição de um grupo socialmente indesejado parece acalmar os ânimos de parte da população. Nesse ponto, é possível fazer um paralelo com o pensamento de Kingdom, tendo em vista que esse aponta que nem sempre a solução apresentada pelo Governo tem como objetivo principal a resolução do problema ao qual foi anexado ${ }^{29}$.

A referida política punitivista, de tratar os adictos como traficantes de drogas, não distinguindo objetivamente quem usa e quem vende os entorpecentes, é reforçada pela própria lei penal. Isto porque, a Lei 11.343/2006, embora confira tratamento diferenciado aos usuários e traficantes de drogas, não estabelecendo pena restritiva de liberdade para aqueles, não estabelece critérios claros e precisos de diferenciação. A consequência disso é que há enorme arbitrariedade na mão dos juízes (no julgamento) e dos promotores públicos (no oferecimento da denúncia) para definir quem é usuário e quem é traficante. Nesse sentido, há um recorte de classe e de raça claro na prática forense, ao encarcerar os pobres e negros e caracterizá-los como traficantes e denominar os mais abastados e brancos como usuários. ${ }^{30}$ Assim, ainda que tal lei tenha sido editada, em tese, para diminuir o encarceramento relacionado ao tráfico e despenalizar os usuários de drogas, o efeito prático enveredou-se em caminhos contrários a esse ideal.

Tendo em vista a presente discussão, vale fazermos alguns apontamentos sobre a composição química do crack. Embora pareça, de acordo com as mensagens enviadas pelo governo e pela mídia, que o crack é uma droga extremamente peculiar, com diferenças grandes em relação a cocaína, um olhar mais atento mostra que se trata da mesma substância utilizada de forma diferente. Dessa

${ }^{29}$ KINGDOM, John W. Agendas, Alternatives and Public Policies. New York: Longman, 1995.

${ }^{30}$ CARVALHO, Salo de. Nas Trincheiras de uma Política Criminal com Derramamento de Sangue: depoimento sobre os danos diretos e colaterais provocados pela guerra às drogas. In: Atendendo na Guerra (Criminologia De Cordel 3) - Dilemas médicos e jurídicos sobre o "crack". Rio de Janeiro: Revan, 2014. 
SOUZA, Matheus Silveira de. A Construção Social do Público Alvo e o desenho da Política Pública: análise comparativa da operação centro legal e do programa de braços abertos. Revista Eletrônica Direito e Política, Programa de Pós-Graduação Stricto Sensu em Ciência Jurídica da UNIVALI, Itajaí, v.14, n.2, $2^{\circ}$ quadrimestre de 2019. Disponível em: www.univali.br/direitoepolitica - ISSN 19807791

forma, tanto o crack como a cocaína possuem o mesmo princípio ativo, benzoilmetilecgonina, sendo que aquele é uma mistura da pasta base de cocaína com bicarbonato de sódio. Trata-se, assim, de uma nova forma de uso para uma substância muito antiga ${ }^{31}$. A visão demoníaca que o crack carrega, tão bem internalizada na sociedade, tem mais relação com a construção social feita sobre a droga do que com dados relacionados a própria substância. Dentre as diversas explicações para essa afirmação, uma que parece elucidar bastante o caso é a que refere-se as diferenças entre os grupos sociais que tipicamente usam a cocaína e o crack.

\section{PRIMEIRAS CONSIDERAÇÕES SOBRE O PROGRAMA DE BRAÇOS ABERTOS}

Visando traçar uma análise comparativa entre as políticas públicas desenvolvidas, em busca de identificar a distribuição de benefícios e encargos, bem como o encaixe do público alvo nas caracterizações já explanadas, será realizada uma análise da política pública "De Braços Abertos", instituída pela Prefeitura de São Paulo. A referida política foi implementada no ano de 2013, na gestão de Fernando Haddad, em consonância com a política do Governo Federal "Crack, é possível vencer".

Em uma primeira análise, aponta-se que o referido programa buscou, pelo menos em tese, firmar uma política mais integrativa, ao oferecer ao público alvo moradia, trabalho, alimentação, higiene, tratamento de saúde e suporte social ${ }^{32}$. Essa prática integrativa é explicada pela articulação de diversas secretarias municipais, como por exemplo, Secretaria de Habitação, Secretaria de Cultura, Secretaria de Educação, Secretaria da Justiça, Secretaria da Saúde, Secretaria de Direitos

\footnotetext{
31 REINARMAN, Craig; LEVINE, Harry. Crack in the rearview: deconstructing drug war mythology. Social Justice. V.31, N 1-2, 2004.

32 FIOCRUZ. Fundação Oswaldo Cruz. Pesquisa Nacional Sobre o Uso de Crack. Organizadores: Francisco Inácio Bastos; Neilane Bertoni. Rio de Janeiro: Editora Icict Fiocruz, 2014.
} 
SOUZA, Matheus Silveira de. A Construção Social do Público Alvo e o desenho da Política Pública: análise comparativa da operação centro legal e do programa de braços abertos. Revista Eletrônica Direito e Política, Programa de Pós-Graduação Stricto Sensu em Ciência Jurídica da UNIVALI, Itajaí, v.14, n.2, $2^{\circ}$ quadrimestre de 2019. Disponível em: www.univali.br/direitoepolitica - ISSN 19807791

Humanos e Cidadania, entre outras, que atuavam em conjunto para atingir os objetivos do programa. ${ }^{33}$

Uma das diferenças principais que pode ser encontradas entre a "Operação Centro Legal" e o programa "De Braços Abertos" é que enquanto aquela partia de uma premissa de abstinência dos usuários, esta guardava foco para a perspectiva da redução de danos. Dessa forma, buscava-se ofertar um "pacote de direitos básicos", composto por moradia, emprego e renda, com exigências e condições mínimas por parte dos usuários do programa. Portanto, não exigia-se que os sujeitos estivessem "livres" do consumo de crack para a concessão dos benefícios, de modo que pode-se visualizar o enfoque menos na problemática das drogas e mais na promoção do sujeito e da sua dimensão social.

\section{CONSTRUÇÃo SOCIAL E DESENHO DA POLÍtica PÚblica No PROGRAMA DE BRAÇOS ABERTOS}

Tendo como referencial teórico o quadro de análise de Ingram, Schneider e Deleon traduzido e ilustrado anteriormente (capítulo 1, página 4), cumpre aplicá-lo no programa ora analisado. Assim, a linha vertical do quadro, que media a influência política do grupo, não parece ter alterações, sendo que a extrema vulnerabilidade e fragilidade social dos usuários de crack possibilitam pouco ou nenhum capital político. Todavia, pode ser encontrado uma diferença no encaixe dos usuários de crack em relação a linha horizontal, que media a imagem do grupo como merecedores ou não de benefícios, se comparada com a operação Centro Legal.

Assim, dado as 4 caracterizações já explanadas (vantajosos, competidores, dependentes e desviantes), o programa "De Braços Abertos" pareceu ter inserido esses sujeitos no grupo dos dependentes, e não mais dos desviantes. Assim, complementando o quadro analítico apontado com a tabela de Ingram e Schneider na Revista American Political Science Review, o grupo de dependentes possui a imagem pessoal de desamparados e necessitados, sendo que o governo costuma

33 PREFEITURA DO MUNICÍPIO DE SÃO PAULO. O Programa De Braços Abertos, 2013. 
SOUZA, Matheus Silveira de. A Construção Social do Público Alvo e o desenho da Política Pública: análise comparativa da operação centro legal e do programa de braços abertos. Revista Eletrônica Direito e Política, Programa de Pós-Graduação Stricto Sensu em Ciência Jurídica da UNIVALI, Itajaí, v.14, n.2, $2^{\circ}$ quadrimestre de 2019. Disponível em: www.univali.br/direitoepolitica - ISSN 19807791

os tratar com piedade e seus problemas são enxergados como de responsabilidade do setor privado. ${ }^{34}$

No programa em análise, a tabela harmoniza-se com a imagem pessoal (desamparados) e o tratamento conferido pelo governo (piedade), não encontrando tanto amparo em relação à descrição da responsabilidade (setor privado). Isto porque, o governo não pareceu terceirizar a responsabilidade sobre o problema exclusivamente para o setor privado ou terceiro setor, concretizando ações públicas no que tange à distribuição de benefícios que pudessem solucionar ou atenuar o problema. Ainda que a comparação seja realizada entre uma política estadual ( "Centro Legal") e uma municipal ( "De Braços Abertos"), o que torna possível a contrastação é que ambas tratavam do problema do crack em âmbito municipal, focando na cidade de São Paulo.

Diante das afirmações e inferências realizadas, pode-se perguntar: quais elementos tornam possível a transição de um grupo do rótulo de desviantes para o de dependentes? Ainda, quais condições materiais tornaram possível uma mudança substancial na política pública?

Não buscando esgotar o assunto, mas sim lançar alguma hipótese à questão apresentada, aponta-se que esse encaixe dos usuários de crack no grupo dos dependentes pode ser explicado pelo foco conferido em relação ao contexto social, econômico e cultural desses sujeitos, partindo da premissa de que a a causa principal da dependência química são os problemas de ordem social e familiar, anteriores ao uso da droga. ${ }^{35}$

A própria prática da redução de danos é mais condizente com essa visão e dá maiores fundamentos para que essa transição seja feita. A pergunta que está pintada nesse pano de fundo problemático - que está por trás da comparação entre os dois programas - é se o obstáculo a ser superado deve ser tratado como um

34 INGRAM, Helen; SCHNEIDER, Anne. Social Construction of target Populations: Implications for Politics and Policy. In: The American Political Science Review, Vol. 87, N. 2, p. 334-347. 1993.

35 BOYD, Carol. The Antecedents of Women's Crack Cocaine Abuse: Family Substance Abuse, Sexual Abuse, Depression and Illicit Drug Use. Journal of Substance Abuse Treatment, V. 10, pp. 433438,1993 
SOUZA, Matheus Silveira de. A Construção Social do Público Alvo e o desenho da Política Pública: análise comparativa da operação centro legal e do programa de braços abertos. Revista Eletrônica Direito e Política, Programa de Pós-Graduação Stricto Sensu em Ciência Jurídica da UNIVALI, Itajaí, v.14, n.2, $2^{\circ}$ quadrimestre de 2019. Disponível em: www.univali.br/direitoepolitica - ISSN 19807791

problema social e de saúde ou como um problema estritamente de segurança pública.

A Pesquisa Nacional sobre o uso de crack realizada pelo Ministério da Saúde e pela Fundação Oswaldo Cruz dá alguns dados que ajudam a diagnosticar o problema do enfrentamento da questão do crack, ao indicar que $80 \%$ dos usuários de crack são não brancos e possuem baixa escolaridade. ${ }^{36}$ Mais especificamente, apenas 16,49\% dos usuários cursaram/completaram o Ensino Médio e 57\% cursaram o Ensino Fundamental. A porcentagem dessa população que completou o Ensino Superior é de apenas $2 \% .{ }^{37}$ Em relação a moradia, a pesquisa aponta que $39,04 \%$ dos usuários moram na rua.

Outro ponto que merece destaque para a compreensão da mudança na política pública está presente na obra de True, D. Jones e Baumgartner - Punctuated Equilibrium Theory $^{38}$ - que aborda as condições materiais que tornam possível mudanças mais substanciais nas policies. Nesse sentido, um dos pontos centrais apontado pelos autores, que permitem tais alterações, é a entrada do problema na agenda macropolítica, não se restringindo mais ao âmbito dos subsistemas. Essa entrada faz com que pequenas mudanças causem grande impacto na policy. Assim, utilizando-se do exemplo da entrada do "problema-crime" na agenda macropolítica dos EUA, os autores apontam três medidas importantíssimas para essa inserção, quais sejam: (a) a cobertura da imprensa sobre o assunto, (b) a proporção de cidadãos dizendo que o crime é o problema mais importante que a nação enfrenta e (c) a realização de audiências no Congresso abordando a questão.

Traçando um paralelo sobre a mudança ocorrida entre a operação "Centro Legal" e o programa "De Braços Abertos", alguns pontos de conexão podem ser encontrados. Nesse sentido, das três condições acima destacadas, ao menos duas,

\footnotetext{
36 FIOCRUZ. Fundação Oswaldo Cruz. Pesquisa Nacional Sobre o Uso de Crack. Organizadores: Francisco Inácio Bastos; Neilane Bertoni. Rio de Janeiro: Editora Icict Fiocruz, 2014.

37 FIOCRUZ. Fundação Oswaldo Cruz. Pesquisa Nacional Sobre o Uso de Crack. Organizadores: Francisco Inácio Bastos; Neilane Bertoni. Rio de Janeiro: Editora Icict Fiocruz, 2014

38 TRUE, James L; JONES, Bryan D; BAUMGARTNER, Frank R. Punctuated-Equilibrium Theory: Explaining Stability and Change in Public Policymaking. In: SABATIER, Paul (ed.) - Theories of Policy Process - Boulder: Westview Press, 2007
} 
SOUZA, Matheus Silveira de. A Construção Social do Público Alvo e o desenho da Política Pública: análise comparativa da operação centro legal e do programa de braços abertos. Revista Eletrônica Direito e Política, Programa de Pós-Graduação Stricto Sensu em Ciência Jurídica da UNIVALI, Itajaí, v.14, n.2, $2^{\circ}$ quadrimestre de 2019. Disponível em: www.univali.br/direitoepolitica - ISSN 19807791

"a" e "b", podem ser encontradas no contexto das políticas públicas de São Paulo. Em relação a abordagem da mídia sobre a questão, fora discorrido no trabalho, mais de uma vez, sobre o papel desempenhado pela imprensa, ao apontar incessantemente o problema do crack no município de São Paulo, bem como ao ajudar na construção social desse problema como uma epidemia nacional.

Sobre a dimensão problemática que a população dava à questão, ressalta-se que em pesquisa realizada pelo Data Folha em 2013, que investigava a evolução do medo dos paulistanos ${ }^{39}$, dentre as alternativas (1) ter a casa invadida por assaltantes, (2) que os jovens da família se envolvam com tóxicos, (3) ser assaltado na rua, (4) alto custo de vida e (5) perder o emprego, a alternativa que aparecia como mais apontada foi a (2) - que os jovens da família se envolvam com tóxicos - escolhida por $45 \%$ dos entrevistados.

Dessa forma, das 3 condições apontadas por True, D. Jones e Baumgartner que permitem a inserção do problema na agenda macropolítica, com consequente possibilidade de mudanças substanciais na política pública, é possível visualizar que duas estão presentes no contexto de São Paulo. Ainda sobre essa inserção, não se pode olvidar que a elaboração do Governo Federal, em 2013, do programa "Crack, é possível vencer", bem como o fato do prefeito Fernando Haddad pertencer ao PT, mesmo partido da Presidente da República na época, Dilma Roussef, facilitam a articulação entre os entes federativos para a entrada do problema na agenda macropolítica. Essa harmonia partidária não era visualizada na ação governamental anterior, tendo em vista que Serra era filiado ao PSDB, partido de oposição do Governo Federal. Kassab, por sua vez, pertencia ao DEM. Por fim, uma questão que deve ser considerada é a da mudança do chefe do executivo no município de São Paulo em virtude das eleições de 2012, o que abre algum espaço para a mudança substancial nas políticas públicas da cidade.

No que tange a construção do problema, embora haja uma mudança de foco no enfrentamento deste, há que se destacar que o governo continuou usando a ideia do crack como uma epidemia social. Embora não seja o foco desse trabalho a

39 DATA FOLHA. 30 anos: medo dos paulistanos. Documento P0813680, 25 e 26 de abril de 2013. Disponível em: < http://media.folha.uol.com.br/datafolha/2013/05/03/datafolha- 30-anos-medodos-paulistanos.pdf> Acessado em 17/07/2017. 
SOUZA, Matheus Silveira de. A Construção Social do Público Alvo e o desenho da Política Pública: análise comparativa da operação centro legal e do programa de braços abertos. Revista Eletrônica Direito e Política, Programa de Pós-Graduação Stricto Sensu em Ciência Jurídica da UNIVALI, Itajaí, v.14, n.2, $2^{\circ}$ quadrimestre de 2019. Disponível em: www.univali.br/direitoepolitica - ISSN 19807791

desmistificação da chamada "epidemia do crack", diversas pesquisas apontam que a epidemia relacionada ao crack é mais uma mistificação do que uma realidade ${ }^{40}$ 41, de forma que tal imagem é construída para dar outras dimensões à situação.

\section{CONSIDERAÇÕES FINAIS}

Diante do desenvolvimento realizado nos capítulos precedentes, algumas conclusões podem ser extraídas. Primeiramente, embora a Constituição estabeleça que todos são iguais perante a lei, observa-se que os policymakers tratam de forma diferente as pessoas quando da elaboração e execução de políticas públicas, tendo em vista que a distribuição de benefícios e encargos variará de acordo com o grupo que será alvo da ação governamental. Dessa forma, um bom parâmetro para medir a possibilidade de êxito de um grupo em uma política pública é a aferição de sua influência política e da construção social de sua imagem como merecedor ou não de benefícios. Entretanto, ressalta-se que a política pública é sempre permeada por diversos fatores, como indicadores sociais, contexto político, janelas de oportunidades, crise financeira, ações judiciais envolvendo políticos, crises naturais, entre outras, sendo a construção social e o capital político dos grupos um fator importante, mas dependente de outras variáveis.

Evidenciou-se, ainda, como o encaixe de um público alvo em uma ou outra categoria - vantajosos, contendores, dependentes e desviantes - terá grande importância na elaboração do desenho da policy (sendo sua recíproca verdadeira), bem como na distribuição de benefícios. Tal afirmação é explicitada na comparação da operação "Centro Legal" com o programa "De Braços Abertos", tendo em vista que a mudança do público alvo da categoria de desviantes para a de dependentes permite uma mudança significativa no enfrentamento do problema, como também na distribuição de benefícios. Assim, ainda que a dimensão da influência política

40 CARVALHIDO, Anna Luísa. O estigma e o poder do conhecimento: um estudo sobre a operação Centro Legal de 2012. 2014. 138 f. (Dissertação) Mestrado em Direito. Faculdade de Direito, Fundação Getúlio Vargas, São Paulo. 2014

41 REINARMAN, Craig. The Social Construction of Drug Scare. Wadsworth Publishing Co. 1994 
SOUZA, Matheus Silveira de. A Construção Social do Público Alvo e o desenho da Política Pública: análise comparativa da operação centro legal e do programa de braços abertos. Revista Eletrônica Direito e Política, Programa de Pós-Graduação Stricto Sensu em Ciência Jurídica da UNIVALI, Itajaí, v.14, n.2, $2^{\circ}$ quadrimestre de 2019. Disponível em: www.univali.br/direitoepolitica - ISSN 19807791

do grupo não tenha sido alterada, a mudança na construção social de sua imagem já constitui uma diretriz importante para transformações da ação governamental.

Por conseguinte, a operação "Centro Legal" concentrou-se na distribuição não só de encargos, mas também de sanções aos usuários de crack, traduzidos na repressão policial aplicada na região da denominada cracolândia e verificada pela posição central que a Polícia Militar ocupava na ação governamental. A partilha de benefícios ocorreu de maneira mais tímida, eis que as abordagens e atendimentos realizados deram mais atenção para a dimensão quantitativa em detrimento da dimensão qualitativa. Assim, a distribuição de poucos benefícios e muitas sanções harmoniza-se com a prática frequentemente concedida à categoria dos desviantes.

No que se refere ao programa "De Braços Abertos", pode-se notar uma diferença na partilha de benefícios e encargos. Isto porque, a alteração da categoria dos desviantes para os dependentes, conjugada com uma política de redução de danos, permitiu uma maior distribuição de benefícios, traduzidos na concessão de emprego, renda, moradia, assistência social e saúde aos usuários de crack. Ainda que o programa "De Braços Abertos" partisse de um diagnóstico questionável - o uso do crack enquanto epidemia - o enfrentamento do problema focado em questões sociais e de saúde, e não apenas em uma questão de segurança pública, possibilitou a apresentação de uma solução mais adequada e efetiva ao problema diagnosticado ${ }^{42}$.

Não se deve ignorar que o problema relacionado ao uso do crack ainda persiste em São Paulo, cabendo ao Estado o aprimoramento de políticas públicas para buscar alternativas. Embora o programa "De Braços Abertos" tenha apresentado resultados positivos no que tange à diminuição do uso da droga por parte dos usuários, como também uma paulatina inserção social destes, ainda há muito para ser construído e desenvolvido para o enfrentamento da questão. Nesse sentido, ainda que possamos verificar a persistência do problema, a política desenvolvida pelo programa "De Braços Abertos" apontou diretrizes eficientes para lidar com a

\footnotetext{
42Evans L. Opção humanitária, $2014 . \quad$ Disponível em: http://www1.folha.uol.com.br/opiniao/2014/02/1412570-liz--evans-opcao-humanitaria.shtml
} 
SOUZA, Matheus Silveira de. A Construção Social do Público Alvo e o desenho da Política Pública: análise comparativa da operação centro legal e do programa de braços abertos. Revista Eletrônica Direito e Política, Programa de Pós-Graduação Stricto Sensu em Ciência Jurídica da UNIVALI, Itajaí, v.14, n.2, $2^{\circ}$ quadrimestre de 2019. Disponível em: www.univali.br/direitoepolitica - ISSN 19807791

questão, levando em conta a necessidade de políticas públicas integrativas e intersetoriais, dando ênfase às ações governamentais sociais e de saúde.

\section{REFERÊNCIA DAS FONTES CITADAS}

BECKER, Howard. Outsiders: studies in the sociology of deviance. New York: Free Press, 1963.

BOYD, Carol. The Antecedents of Women's Crack Cocaine Abuse: Family Substance Abuse, Sexual Abuse, Depression and Illicit Drug Use. Journal of Substance Abuse Treatment, V. 10, pp. 433-438, 1993

IMERGUT, Ellen. The Rules of the Game: The Logic of Health Policy-Making in France, Switzerland and Sweden. In Thelen and Steinmo, eds., Structuring Politics: Historical Institutionalism in Comparative Perspective. New York: Cambridge University Press, 1992

O núcleo teórico do novo institucionalismo. In Políticas Públicas. Coletânea. (Enrique Saravia e Elisabete Ferrarezi, orgs.), vol. 1. Brasília: ENAP, 2006.

INGRAM, Helen; SCHNEIDER, Anne; DELEON, Peter. Social Construction and Policy Design. In: SABATIER, Paul (ed.) - Theories of Policy Process - Boulder: Westview Press, 2007.

INGRAM, Helen; SCHNEIDER, Anne. Social Construction of target Populations: Implications for Politics and Policy. In: The American Political Science Review, Vol. 87, N. 2, p. 334-347. 1993.

CARVALHIDO, Anna Luísa. O estigma e o poder do conhecimento: um estudo sobre a operação Centro Legal de 2012. 2014. 138 f. (Dissertação) Mestrado em Direito. Faculdade de Direito, Fundação Getúlio Vargas, São Paulo. 2014

CARVALHO, Salo de. Nas Trincheiras de uma Política Criminal com Derramamento de Sangue: depoimento sobre os danos diretos e colaterais provocados pela guerra às drogas. In: Atendendo na Guerra (Criminologia De Cordel 3) - Dilemas médicos e jurídicos sobre o "crack". Rio de Janeiro: Revan, 2014.

COHEN, Howard; FELDBERG, Michael. A social contract perspective on the police role. IN: MILLER, Seumas (Org.) Police Ethics. London: Ashgate, 2006.

DANTAS, André. Superpopulação carcerária no Rio de Janeiro regulada pela economia da droga: um efeito da política de criminalização imposta aos 
SOUZA, Matheus Silveira de. A Construção Social do Público Alvo e o desenho da Política Pública: análise comparativa da operação centro legal e do programa de braços abertos. Revista Eletrônica Direito e Política, Programa de Pós-Graduação Stricto Sensu em Ciência Jurídica da UNIVALI, Itajaí, v.14, n.2, $2^{\circ}$ quadrimestre de 2019. Disponível em: www.univali.br/direitoepolitica - ISSN 19807791

jovens residentes das comunidades carentes. Tese de Doutorado da UERJ, Faculdade de Educação. Rio de Janeiro: 2012

DATA FOLHA. 30 anos: medo dos paulistanos. Documento PO813680, 25 e 26 de abril de 2013. Disponível em: <http://media.folha.uol.com.br/datafolha/2013/05/03/datafolha- 30-anos-medodos-paulistanos.pdf> Acessado em 17/07/2017.

ECO, Umberto. Como fazer uma tese. Tradução de Gilson César Cardoso de Souza São Paulo: Perspectiva, 2005.

FIOCRUZ. Fundação Oswaldo Cruz. Pesquisa Nacional Sobre o Uso de Crack. Organizadores: Francisco Inácio Bastos; Neilane Bertoni. Rio de Janeiro: Editora Icict Fiocruz, 2014. Disponível em < https://www.arca.fiocruz.br/bitstream/icict/10019/2/UsoDeCrack.pdf > Acesso em: 10/07/2017.

G1. "Um anos após operação no centro de sp cracolandia resiste e fanha filiais", de 03 de janeiro de 2012. Disponível em: http://g1.globo.com/saopaulo/noticia/2013/01/um-ano-apos-operacao-no-centro-de-sp-cracolandiaresiste-e-ganha-filiais.html. Acesso em: 12/07/2017

KINGDOM, John W. Agendas, Alternatives and Public Policies. New York: Longman, 1995, capítulos 4-9.

O ESTADO DE S. PAULO, 4 de janeiro de 2012, "PM ocupa a cracolândia e fará vigilância 24 horas", Página 1.

PREFEITURA DO MUNICÍPIO DE SÃO PAULO. O Programa De Braços Abertos, 2013.

ROMANINI, M.; ROSO, A. O Crack na Mídia Escrita: epidêmico, avassalado e diabólico. In: Anais da $3^{\circ}$ Jornada Interdisciplinar em Saúde. Santa Maria, 2010.

REINARMAN, Craig; LEVINE, Harry. Crack in the rearview: deconstructing drug war mythology. Social Justice. V.31, N 1-2, 2004.

REINARMAN, Craig. The Social Construction of Drug Scare. Wadsworth Publishing Co. 1994

SABATIER, P. A. Theories of the Policy Process. 2. ed. Boulder: Westview Press, 2007 
SOUZA, Matheus Silveira de. A Construção Social do Público Alvo e o desenho da Política Pública: análise comparativa da operação centro legal e do programa de braços abertos. Revista Eletrônica Direito e Política, Programa de Pós-Graduação Stricto Sensu em Ciência Jurídica da UNIVALI, Itajaí, v.14, n.2, $2^{\circ}$ quadrimestre de 2019. Disponível em: www.univali.br/direitoepolitica - ISSN 19807791

The advocacy coalition framework: anassessment. In: SABATIER, P. A. (Ed.). Theories of the Policy Process. Boulder: Westview Press, 1999. p. 117166.

TRUE, James L; JONES, Bryan D; BAUMGARTNER, Frank R. PunctuatedEquilibrium Theory: Explaining Stability and Change in Public Policymaking. In: SABATIER, Paul (ed.) - Theories of Policy Process - Boulder: Westview Press, 2007

RECEBIDO EM: 14/12/2018

APROVADO EM: 19/03/2019 